\title{
Akıllı Telefonların Uygulama İzinleri Üzerine Bir Farkındalık Çalışması ${ }^{1}$
} İhsan KARLI Kocaeli Üniversitesi İletişim Fakültesi Gazetecilik Bölümü, Doç. Dr. ihsankarli@yahoo.com
https://orcid.org/0000-0002-3099-4865

Sema DOĞRU Kocaeli Üniversitesi Kandıra MYO, Halkla İlişkiler ve Tanıtım, Öğr. Gör.semaeker@ outlook.com https://orcid.org/0000-0002-5709-586X

Yusuf Bahadır DOĞRU Kocaeli Üniversitesi Halkla İlişkiler ve Tanıtım Bölümü, Arş. Gör. yusufbd@hotmail.com https://orcid.org/0000-0002-7635-0766

ÖZ Günümüzde mobil iletişim teknolojisi hayatımızın merkezinde yer almaktadır. Bugün akıllı telefonlar hem iş yaşamının hem de günlük yaşamın vazgeçilmez bir parçası haline gelmiştir. Internete yer ve zaman kısıtlaması olmadan ulaşabilen akıllı telefonlar kullanıcı alışkanlıklarını değiştirmeye başlamıştır. Bireyler beğendikleri ve yararlı gördükleri uygulamaları aktif bir şekilde kullanarak cihazlarında muhafaza etmektedirler. Hatta; az kullandıkları veya artık hiç kullanmadıkları uygulamaları bile cihazlarından kaldırmamaktadırlar. Bu da mobil uygulamalara olan ihtiyaç ve bağlılı̆̆ı göstermesi açısından önemlidir. Bireyler mobil cihazlarında kullanmak istedikleri programları indirme faaliyetini gerçekleştirirken, indirme yaptıkları uygulamalar bazı özel izinler talep etmektedir. Bu izinlerin bazıları uygulamanın çalışması için gerekli izinler iken bazıları tehlikeli (özel yaşamın gizliliğini ihlal eden) izinler arasındadır. Her uygulamanın istediği izinler birbirinden farklıdır. Takvim, kamera, rehber, konum bilgisi, telefona gelen çağrilar, mikrofon, mesajlara erişim ve depolama ayarlarn gibi birçok izin uygulama izni olarak talep edilmektedir. Bu izinler verilmediği durumda da uygulamalar çalışmamaktadır. Bu çalışmada, bireylerin uygulama izinleri ile ilgili farkındalıkları ve davranış pratikleri araştırılmıştır. Çalışmanın amacı, bireylerin yükledikleri programlara bu izinleri verip vermediği ve bu izinlerin tehlikelerinden haberdar olup olmama durumlarını tespit etmektir. Bu bağlamda erişim kolayliğı göz önünde bulundurularak örneklem olarak Kocaeli Üniversitesi İletişim Fakültesi öğrencileri tercih edilmiştir. Araştırma kapsamında \%95 güven düzeyi ve \%6 hata payı ile 246 öğrenciden anket tekniği ile veri toplanmıştır. Elde edilen 246 veriden 218'i araştırmaya dahil edilirken; 28 anket geçersiz sayılmıştır.

Anahtar Kelimeler: Akıllı Telefon, Mobil İinler, Farkındalık, Mobil Uygulamalar

\section{An Awareness Study On Application Permits Of Smartphones ${ }^{2}$}

ABSTRACT Nowadays, mobile communication technology is at the center of our life. Today, smartphones have become an indispensable part of both business and daily life. Smartphones that can reach the Internet without space and time constraints have begun to change user habits. Individuals actively use the applications that they like and appreciate, and keep them in their devices. Even; they do not remove applications that they use little or no longer use. This is important in terms of the need and commitment to mobile applications. While downloading the programs they want to use on their mobile devices, the applications they download are asking for special permissions. Some of these permissions are required for the operation of the application, while others are dangerous (violating private secrecy) permissions.

\footnotetext{
${ }^{1}$ Bu çalışma 2. Uluslararası İletişim Bilimi \& Medya Çalışmaları Kongresi'nde bildiri olarak sunulmuştur.

2 This work was presented at the 2nd International Communication Science \& Media Studies Congress.
} 
The permissions each application wants are different. Many permissions such as calendar, camera, contacts, location information, incoming calls to the phone, microphone, access to the messages and storage settings are requested as permission. Applications do not work when these permissions are not granted. In this study, awareness and behavioral practices of individuals will be investigated. The aim of the work is to determine whether individuals have given these permits to programs they have installed, and whether they are aware of the dangers of those permits. Taking into account the ease of access in this context, students from Kocaeli University Faculty of Communication have been chosen as the sample. The data will be collected by the survey technique from the students included in the survey. The survey technique will be applied to 246 people with 95\% confidence level and 6\% error margin.

Keywords: SmartPhone; Mobile Permissions; Awareness, Mobil Applications.

\section{Giriş}

Yeni iletişim teknolojilerinin gelişmesiyle birlikte akıllı telefonlar hayatımızda gün geçtikçe daha fazla yer almaya başlamıştır. Akıllı telefonlar ile birlikte internet teknolojilerinin de hızla gelişimi akıllı telefonları birer kişisel asistanımız haline getirmiştir. Deloitte'ın 2017 yılında 18-50 yaş arası 1005 kişi ile yapmış olduğu “Dijitalleşen Hayatımızda Mobil Teknolojilerin Yeri Global Mobil Kullanıcı" araştırmasında, Türkiye'de akıllı telefon kullanım oranının \%92 olduğu görülmektedir. Aynı araştırmadaki bir başka soruda kişisel bilgilerin şirketler tarafından kullanıldığ düşüncesine sahip kişilerin oranı ise \%63'tür (www2.deloitte.com).

$\mathrm{Bu}$ araştırma sonuçları bize akıllı telefon kullanım oranının neredeyse nüfusun çok büyük bir bölümünün akıllı telefon kullandığını göstermektedir. Bu bağlamda "bireylerin telefonları kullanım biçimleri, uygulama izinleri konusunda farkındalıkları, tehlike bilinci" gibi sorulardan yola çıkarak bu araştırma gerçekleştirilmiştir.

\section{Akıllı Telefonlar ve Uygulama İzinleri}

Akıllı telefonlar, sıradan cep telefonlarına göre daha gelişmiş bilgi işlem gücü sunan, bağlanılabilirliği ve kabiliyetleri yüksek olan mobil aygıtlardır. Kullanıcılarına telefon görüşmeleri yapmalarına olanak sağlamalarını yanında, çoğu bilgisayarlarda bulabilecekleri özellikleri (e-posta gönderip almak, ofis belgelerini düzenlenmesi, kişisel notların tutulması, takvim ile hatırlatma ve planlamaların yapılması vb.) gerçekleştirmelerine imkân tanımaktadır (Kim \& Hovav, 2011). Bu özelliklerin akıllı telefonlar üzerinden kolaylıkla yapılabiliyor olması bireyleri akıllı telefonlara yönlendirmektedir.

Akıllı telefonların ortaya çıkmasıyla birlikte artık telefonların ekranları daha yüksek çözünürlükte ve netliktedir. Bugün neredeyse tüm akıllı telefonlar duyarlı bir dokunmatik ekrana sahiptir. Çoğu telefon yalnızca video çekimi yapabilen değil, bu videolar üzerinde düzenleme özelliğine de sahiptir. Yeni nesil akıllı telefonların çoğu daha hızlı Wi-Fi ile birlikte 4G-5G hücresel bağlantılarına da sahiptir. Akıllı telefonların yerleşik depolama alanları da büyümüştür hatta bazı dizüstü bilgisayarlardan daha yüksek 
kapasiteli hale gelmiştir. Akıllı telefonların birçoğunda, GPS, Bluetooth, pusula, yüksek çözünürlüklü kameralar ve çeşitli sensörler bulunmaktadır (Godwin, 2011, s. 2-3).

Akıllı telefonlar ve bunların sağladıkları özellikler, sadece ticari işletmelerde değil her türlü kuruma fayda sağlayabilmektedir. Bu faydalar kurumlara genel olarak maliyet tasarrufu, verimlilik artışı ve yenilikçilik kabiliyeti olarak yansımaktadır. Akıllı telefonların kurumlara sağladığı faydalar aşağıdaki gibi özetlenebilir (Werdata Inc'den aktaran Ada \& Tatlı, 2013);

- Akıllı telefonlar ile e-mail hesaplarına erişim kolay olmakla birlikte bu maliyetleri azaltıp, verimliliği arttırmaktadır.

- İşletme içindeki sistemlere uzaktan erişim sayesinde gereksiz telefon görüşmeleri ve şirket ziyaretleri azaltılmaktadır.

- Navigasyon kabiliyeti sayesinde ulaşılmak istenen yerlere zaman ve maliyet tasarrufu sağlanarak ulaşılmaktadır.

- GPS fonksiyonu sayesinde mekân paylaşımı ve çalışan takibi sağlanabilmektedir.

- Yüksek çözünürlüklü kameralar iş birliği ve doküman paylaşımını sağlayabilmektedir.

- Wi-Fi özelliği sayesinde ücretsiz internet erişimi sağlanabilmekte ve seyahatlerde internet maliyetlerini azaltabilmektedir.

- Örgütteki sistemler aracılığıyla dışarıdan veri paylaşımı ve transferi gerçekleştirilebilmektedir.

2017 yılında yayınlanan istatistiklere göre Android uygulama mağazası olan Google Play 2 milyon 800 bin, IOS uygulama mağazası olan App Store'de ise 2 milyon 200 bin adet uygulama olduğu görülmektedir (www.teknolojituru.com).

Akıllı telefonlar ile yapılan işlemler telefonun kendi özelliği olduğu gibi bazı işlemleri yapabilmek için çeşitli uygulamaların indirilmesi gerekmektedir. Akıllı telefon uygulamaları indirildiğinde, indirilen bu uygulamaları tam anlamıyla kullanabilmek için de bazı izinler vermemiz gerekmektedir. Başlıca izinler şunlardır;

- Takvim izni, uygulamaya, arkadaşlarınızın ve iş arkadaşlarınızın etkinlikleri de dahil olmak üzere telefonunuzda depolanan tüm takvim etkinliklerini okuma izni verir. $\mathrm{Bu}$ izin, uygulamanın takvim verilerinizi gizliliğine ve hassaslığına bakmaksızın paylaşmasına ve kaydetmesine olanak sağlayabilir.

- Kamera izni, uygulamaya kamerayla fotoğraf ve video çekme izni verir. Bu izin, uygulamanın sizin onayınız olmadan istediği zaman kamerayı kullanmasına olanak sağlar.

- Rehber izni, uygulamaya telefonunuzda depolanan kişilerinizle ilgili verileri okuma izni verir. Bu verilere belirli kişilerle ne sıklıkta çağrı, e-posta veya diğer yöntemlerle iletişim kurduğunuz bilgisi dahildir.

- Konum bilgisi izni, uygulamaya yaklaşık konumunuzu belirleme izni verir.

- Telefon izni, uygulamaya cihazdaki telefon özelliklerine erişme izni verir. Bu izin, uygulamanın telefon numarasını ve cihaz kimliğini, etkin bir çağrı olup olmadığını ve çağrıda bağlanılan karşı tarafın numarasını öğrenmesine olanak sağlar. 
- Mikrofon izni, uygulamaya mikrofonla ses kaydetme izni verir. Bu izin, uygulamanın istediği zaman onayınız olmadan ses kaydetmesine olanak sağlar.

- Mesaj izni, uygulamaya telefonunuzda veya SIM kartınızda saklanan SMS iletilerini okuma izni verir. Bu izin, uygulamanın tüm SMS iletilerini içeriğinden veya gizliliğinden bağımsız olarak okumasına olanak sağlar.

- Depolama/kayıt ayarları izni, uygulamanın SD karta veri kaydetmesine ve bilgi almasina izin verir.

- Galeri izni, uygulamanın, galeride bulunan fotoğraf ve videolara ulaşmasına izin verir.

Bu uygulama izinleri ile kişisel bilgilerin üçüncü kişilerin eline geçme ihtimalinden dolayı özel yaşamın gizliliğini ve mahremiyeti ile tehlikeler ortaya çıkmaktadır.

\section{Bulgular}

Araştırmaya dahil edilen 246 öğrenciden anket tekniği ile toplanan verilerin sonuçları aşağıda yer almaktadır. Elde edilen 246 veriden 218'i araştırmaya dahil edilirken; 28 anket geçersiz sayılmıştır.

Ankete katılan bireylerin \%50,9' u kadın, \%49,1'i erkektir. Ankete katılan bireylerin \%60,6'sı akıllı telefon uygulamalarını 'Her zaman' kullandığını ifade ederken; bireylerin yaklaşık \%29'u 'sıklıkla' ve \%9' u da 'Bazen' kullandığını ifade etmiştir.

Tablo 1. Uygulama İzinlerinin Farkında Olma Durumu

Akılı telefon uygulamalarını indirirken, istenilen uygulama izinlerinin farkında

\begin{tabular}{|c|c|c|c|c|c|}
\hline & & Frequency & Percent & Valid Percent & $\begin{array}{c}\text { Cumulative } \\
\text { Percent }\end{array}$ \\
\hline \multirow{6}{*}{ Valid } & Her zaman & 67 & 30,7 & 31,0 & 31,0 \\
\hline & Sıklıkla & 54 & 24,8 & 25,0 & 56,0 \\
\hline & Bazen & 65 & 29,8 & 30,1 & 86,1 \\
\hline & Nadiren & 25 & 11,5 & 11,6 & 97,7 \\
\hline & Hiçbir zaman & 5 & 2,3 & 2,3 & 100,0 \\
\hline & Total & 216 & 99,1 & 100,0 & \\
\hline Missing & System & 2 & ,9 & & \\
\hline Total & & 218 & 100,0 & & \\
\hline
\end{tabular}

Akıllı telefon uygulamaların indirirken, istenilen uygulama izinlerinin 'Her zaman ve 'Sıklıkla' farkında olan bireylerin oranı \%55.5 iken, 'Nadiren' ve 'Hiçbir zaman' seçeneklerinin oranı $\% 13.8$ oranındadır. 
Tablo 2. Uygulama İzinlerinin İçeriğini Okuma Durumu Uygulama izinlerinin neyi kapsadığını okuyor musunuz?

\begin{tabular}{|ll|r|r|r|r|}
\hline & Frequency & Percent & Valid Percent & $\begin{array}{c}\text { Cumulative } \\
\text { Percent }\end{array}$ \\
\hline & Her zaman & 31 & 14,2 & 14,3 & 14,3 \\
& Sıklıkla & 30 & 13,8 & 13,8 & 28,1 \\
Valid & Bazen & 76 & 34,9 & 35,0 & 63,1 \\
& Nadiren & 51 & 23,4 & 23,5 & 86,6 \\
& Hiçbir zaman & 29 & 13,3 & 13,4 & 100,0 \\
& Total & 217 & 99,5 & 100,0 & \\
Missing & System & 1 &, 5 & & \\
Total & & 218 & 100,0 & & \\
\hline
\end{tabular}

Tablo incelendiğinde, ankete katılan bireylerin uygulamaları indirdikten sonra istediğini izinlerin neyi kapsadığını okumadığı sonucu ortaya çıkmıştır. Bireylerin yaklaşık \%23'ü 'Nadiren' okuduğunu ifade ederken, yaklaşık \%13'ü de 'Hiçbir zaman' okumadığını ifade etmiştir. 'Her zaman' ve 'Sıklıkla' yanıtını verenlerin toplam oranı \%28 iken; 'Nadiren' ve 'Hiçbir zaman' yanıtını verenlerin toplam oranı yaklaşık \%37'dir. Buna göre bireylerin, indirdikleri uygulamalar tarafından istenilen izinlerin farkında olduğu ancak, bu izinlerin içeriğini okumadıkları sonucunu çıkarmak mümkündür.

Tablo 3. Özel İzin Gerektiren Uygulamaların Kabul Edilme Durumu Özel izin gerektiren uygulamaları kabul ediyor musunuz?

\begin{tabular}{|ll|r|r|r|r|}
\hline & Frequency & Percent & Valid Percent & $\begin{array}{c}\text { Cumulative } \\
\text { Percent }\end{array}$ \\
\hline \multirow{2}{*}{ Her zaman } & 16 & 7,3 & 7,5 & 7,5 \\
& Sildıka & 27 & 12,4 & 12,6 & 20,1 \\
& Bazen & 85 & 39,0 & 39,7 & 59,8 \\
& Nadid & 60 & 27,5 & 28,0 & 87,9 \\
& Hiçbir zaman & 26 & 11,9 & 12,1 & 100,0 \\
& Total & 214 & 98,2 & 100,0 & \\
Missing & System & 4 & 1,8 & & \\
Total & & 218 & 100,0 & & \\
\hline
\end{tabular}

Özel izin gerektiren uygulamaların kabul edilme durumu sorusuna verilen cevaplara bakıldığında, bireylerin özel izin gerektiren uygulamaları yaklaşık olarak \%40 oranında "nadiren ve hiçbir zaman kabul etmediği" ortaya çıkmıştır. Çalışmaya katılan bireylerin yaklaşık \%20'si ise "her zaman ve sıklıkla" kabul ettiğini söylemiştir. Yaklaşık \%40 oranında ise "bazen" özel izinleri kabul ettiklerini söylemişlerdir.

Tablo 4. Özel İzin Gerektirdiği İçin Yüklemekten Vazgeçilen Uygulama 
Özel izin gerektirdiği için yüklemekten vazgeçtiğiniz bir uygulama oldu mu?

\begin{tabular}{|ll|r|r|r|r|}
\hline & Frequency & Percent & Valid Percent & $\begin{array}{c}\text { Cumulative } \\
\text { Percent }\end{array}$ \\
\hline Her zaman & 21 & 9,6 & 9,8 & 9,8 \\
& Sıklıkla & 42 & 19,3 & 19,6 & 29,4 \\
Valid & Bazen & 83 & 38,1 & 38,8 & 68,2 \\
& Nadiren & 49 & 22,5 & 22,9 & 91,1 \\
& Hiçbir zaman & 19 & 8,7 & 8,9 & 100,0 \\
& Total & 214 & 98,2 & 100,0 & \\
Missing System & 4 & 1,8 & & \\
Total & & 218 & 100,0 & & \\
\hline
\end{tabular}

Bireylere, özel izin gerektirdiği için yüklemekten vazgeçtikleri uygulamalar sorulduğunda 'Her zaman' ve 'Sıklıkla' yanıtını verenlerin toplamı yaklaşık \%30 iken; 'nadiren' ve 'hiçbir zaman' yanıtını verenlerin toplamı yaklaşık \%31'dir.

Tablo 5. Özel Yaşamın Gizliliğini İhlal Etme Durumu Bu izinlerin özel yașamın gizliliğini ihlal ettiğini düşünüyor mu sunuz?

\begin{tabular}{|ll|r|r|r|r|}
\hline & Frequency & Percent & Valid Percent & $\begin{array}{c}\text { Cumulative } \\
\text { Percent }\end{array}$ \\
\hline \multirow{2}{*}{ Her zaman } & 64 & 29,4 & 30,0 & 30,0 \\
& Sıklıkla & 33 & 15,1 & 15,5 & 45,5 \\
& Bazen & 74 & 33,9 & 34,7 & 80,3 \\
Valid & Nadiren & 33 & 15,1 & 15,5 & 95,8 \\
& Hiçbir zaman & 9 & 4,1 & 4,2 & 100,0 \\
& Total & 213 & 97,7 & 100,0 & \\
Missing & System & 5 & 2,3 & & \\
Total & & 218 & 100,0 & & \\
\hline
\end{tabular}

Bireylere, mobil uygulamaları indirirken istenilen izinlerin özel yaşamın gizliliğini ihlal edip etmeme düşünceleri sorulduğunda, 'her zaman' ve 'sıklıkla' yanıtını vererek özel yaşamın gizliliğini ihlal ettiğini düşünenlerin oranı $\% 44,5$ 'dir. İhlal etmediğini düşünenlerin oranı, bu oranın neredeyse yarısıdır.

Bireylerin çoğunluğu istenilen izinlerin özel yaşamın gizliliğini tehdit ettiğinin bilincinde fakat, özel izin gerektirdiği için yüklemekten vazgeçenlerin oranı ile vazgeçmeyenlerin oranı (Tablo 4) neredeyse birbirine eşittir. Bu durum bize tehlikenin farkında olduğu halde, önlem almayan bir akıllı telefon kullanıcı profilini yansıtmaktadır. 
Tablo 6. İzinlerin Gereksiz Olma Durumu

Akılı telefon uygulamalarını indirirken istenilen bazı izinlerin gereksiz olduğunu

\begin{tabular}{|ll|r|r|r|r|}
\hline & & düşünüyor musunuz? & \\
& & Frequency & Percent & Valid Percent & $\begin{array}{c}\text { Cumulative } \\
\text { Percent }\end{array}$ \\
\hline \multirow{4}{*}{ Valid } & Her zaman & 65 & 29,8 & 30,2 & 30,2 \\
& Sıklıkla & 74 & 33,9 & 34,4 & 64,7 \\
& Bazen & 46 & 21,1 & 21,4 & 86,0 \\
& Nadiren & 18 & 8,3 & 8,4 & 94,4 \\
& Hiçbir zaman & 12 & 5,5 & 5,6 & 100,0 \\
Missing & Sotal & 215 & 98,6 & 100,0 & \\
Total & & 3 & 1,4 & & \\
\hline
\end{tabular}

Ankete katılan bireylerin yarısından fazlası, akıllı telefon uygulamalarını indirirken istenilen bazı izinlerin gereksiz olduğunu düşünmektedir.

Tablo 7. İstenilen İzinlerin Önemsenme Durumu

Akıllı telefon uygulamalannı ind irirken istenilen izinleri önemsiyor mu sunuz?

\begin{tabular}{|ll|r|r|r|r|}
\hline & Frequency & Percent & Valid Percent & $\begin{array}{c}\text { Cumulative } \\
\text { Percent }\end{array}$ \\
\hline \multirow{2}{*}{ Her zaman } & 42 & 19,3 & 19,4 & 19,4 \\
& Sıklıkla & 57 & 26,1 & 26,3 & 45,6 \\
Valid & Bazen & 72 & 33,0 & 33,2 & $\mathbf{7 8 , 8}$ \\
& Nadiren & 32 & 14,7 & 14,7 & 93,5 \\
& Hiçbir zaman & 14 & 6,4 & 6,5 & 100,0 \\
Missing & Sotal & 217 & 99,5 & 100,0 & \\
Total & System & 218 & 100,0 & & \\
\hline
\end{tabular}

Ankete katılan bireylerin yaklaşık \%45'i, akıllı telefon uygulamalarını indirirken istenilen izinleri önemsediğini ifade ederken; \%21' i önemsemediğini ifade etmektedir.

Tablo 8. En Çok Kullanılan Mobil Uygulamalar 


\begin{tabular}{|c|c|c|c|c|}
\hline & \multicolumn{2}{|c|}{ Responses } & \multirow{2}{*}{$\begin{array}{c}\text { Percent of } \\
\text { Cases }\end{array}$} \\
\hline & & $\mathbf{N}$ & Percent & \\
\hline \multirow{15}{*}{ Scokluyanit" } & Oyunlar & 134 & $\mathbf{8 , 4} \%$ & $61,8 \%$ \\
\hline & Sağlık uygulamaları & 50 & $3.1 \%$ & $23.0 \%$ \\
\hline & Mobil bankacilık & 163 & $10,2 \%$ & $75,1 \%$ \\
\hline & Güvenlik programiarı & 45 & $2,8 \%$ & $20.7 \%$ \\
\hline & Fal uygulaması & 58 & $3.6 \%$ & $26.7 \%$ \\
\hline & Görsel tasarım uygulamaları & 83 & $5.2 \%$ & $38.2 \%$ \\
\hline & $\begin{array}{l}\text { Sosyal medya } \\
\text { uygulamalan }\end{array}$ & 199 & $12,5 \%$ & $\mathbf{9 1 , 7 \%}$ \\
\hline & Müzil/film uygulamalan & 149 & $9,3 \%$ & $68,7 \%$ \\
\hline & Hava durumu uygulamalan & 89 & $5.6 \%$ & $41.0 \%$ \\
\hline & E-posta uygulamaları & 149 & $9,3 \%$ & $68,7 \%$ \\
\hline & $\begin{array}{l}\text { Online alışveris } \\
\text { uygulamaları }\end{array}$ & 98 & $6.0 \%$ & $44,2 \%$ \\
\hline & $\begin{array}{l}\text { Gazete ve TwRadyo Kanal } \\
\text { Uygulamaları }\end{array}$ & 116 & $7,3 \%$ & $53,5 \%$ \\
\hline & $\begin{array}{l}\text { Harita ve Navigasyon } \\
\text { Uygulamaları }\end{array}$ & 135 & $8,5 \%$ & $62,2 \%$ \\
\hline & $\begin{array}{l}\text { Online bilet alısveris } \\
\text { uygulamaları }\end{array}$ & 65 & $4.1 \%$ & $30.0 \%$ \\
\hline & Diğer uygulamalar & 64 & $4.0 \%$ & $29.5 \%$ \\
\hline Total & & 1595 & $100.0 \%$ & $735,0 \%$ \\
\hline
\end{tabular}

Tablo 8'de katılımcıların en çok kullandığı mobil uygulamalar yer almaktadır. Ankete katılan bireylerin yaklaşık \%92' si sosyal medya uygulamalarını kullandığını ifade etmiştir. İkinci sırada ise \%75 ile mobil bankacılık uygulamaları gelmektedir. Üçüncü olarak kullanılan uygulamalar ise \%68.7 oranı ile müzik/film ve e-posta uygulamalarıdır.

Tablo 9. İstenilen Uygulama İzinleri

\begin{tabular}{|c|c|c|c|c|}
\hline & & \multicolumn{2}{|c|}{ Responses } & \multirow[t]{2}{*}{ Percent of Cases } \\
\hline & & $\mathrm{N}$ & Percent & \\
\hline \multirow{10}{*}{ Syenia } & Takvim & 31 & $3.0 \%$ & $14.4 \%$ \\
\hline & Kamera & 174 & $17,1 \%$ & $80,6 \%$ \\
\hline & Rehber & 98 & $9.6 \%$ & $45.4 \%$ \\
\hline & Konum bilgisi & 187 & $18,4 \%$ & $86,6 \%$ \\
\hline & Telefon & 90 & $8.8 \%$ & $41.7 \%$ \\
\hline & Mikrofon & 131 & $12,9 \%$ & $60,6 \%$ \\
\hline & Mesaj & 42 & $4.1 \%$ & $19.4 \%$ \\
\hline & Depolama/kayıt ayarları & 95 & $9.3 \%$ & $44.0 \%$ \\
\hline & Galeri & 162 & $15,9 \%$ & $75,0 \%$ \\
\hline & Fikrim yok & 7 & $0.7 \%$ & $3.2 \%$ \\
\hline Total & & 1017 & $100.0 \%$ & $470.8 \%$ \\
\hline
\end{tabular}

Bireyler, indirdikleri programlarda istenilen uygulama izinlerini sıraladığında, \%86.6 ile en çok konum bilgisi izni istenildiğini ifade etmiştir. İkinci olarak yaklaşık \%81 oranı ile kameraya ulaşım izni istenildiğini belirtmişlerdir. Üçüncü olarak ise katılımcıların \%75'i uygulamaların galeriye erişim izni istediğini ifade etmiştir.

Tablo 10. Kabul Edilen İzin Türleri 


\begin{tabular}{|c|c|c|c|c|}
\hline & & \multicolumn{2}{|c|}{ Rosponsos } & \multirow{2}{*}{$\begin{array}{c}\text { Porcont of } \\
\text { Cases } \\
\end{array}$} \\
\hline & & $\mathrm{N}$ & Porcont & \\
\hline \multirow{10}{*}{ \$soruonikia } & Takvim & 68 & $9.3 \%$ & $31,5 \%$ \\
\hline & Kamera & 130 & $17,8 \%$ & $60,2 \%$ \\
\hline & Rohber & 46 & $6,3 \%$ & $21,3 \%$ \\
\hline & Konum bilgisi & 119 & $16,3 \%$ & $55,1 \%$ \\
\hline & Telefon & 48 & $6,6 \%$ & $22,2 \%$ \\
\hline & Mikrofon & 106 & $14,5 \%$ & $49,1 \%$ \\
\hline & Mesaj & 28 & $3,8 \%$ & $13,0 \%$ \\
\hline & Depolama/kayıt ayarları & 67 & $9,2 \%$ & $31,0 \%$ \\
\hline & Galeri & 102 & $14,0 \%$ & $47,2 \%$ \\
\hline & $\begin{array}{l}\text { Hiçbirini kabul } \\
\text { etmiyorum }\end{array}$ & 16 & $2,2 \%$ & $7,4 \%$ \\
\hline Total & & 730 & $100.0 \%$ & $338.0 \%$ \\
\hline
\end{tabular}

Tablo 10'da kabul edilen uygulama izinlerine bakıldı̆̆ında, en çok kabul edilen uygulama izinleri olarak \%60.2 ile kamera, \%55.1 ile konum bilgisi, \%14,5 ile mikrofon ve \%14 ile galeri kabul edilen uygulama izinleri içerisinde bulunmaktadır.

Tablo 11. Kabul Edilmeyen Uygulama İzinleri

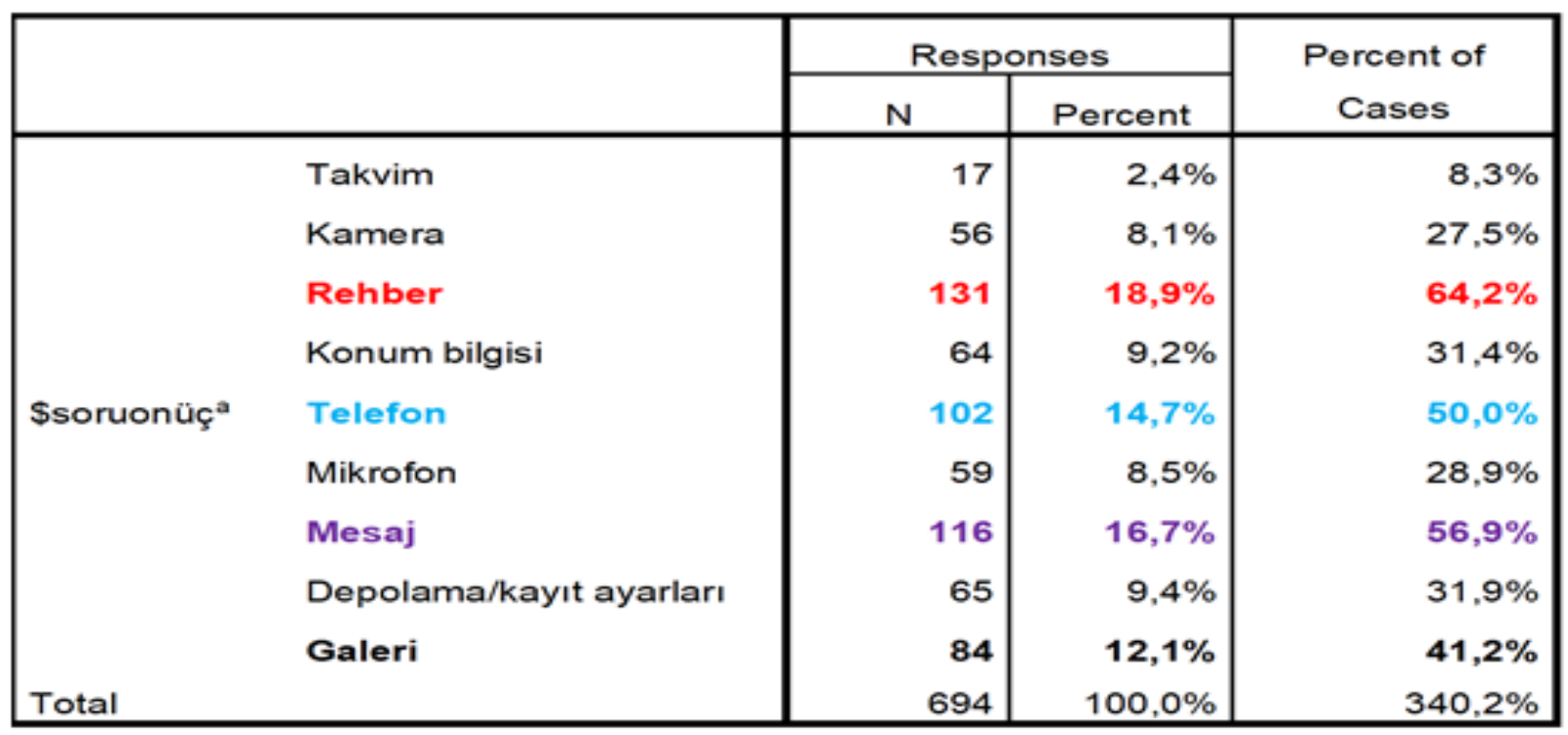

Kabul edilmeyen uygulama izinleri içerisinde, \%64.2 ile rehber, \%56,9 ile mesaj, \%50 ile telefon ve \%41,2 ile galeri bulunmaktadır.

Tablo 10 ve Tablo 11 karşılaştırıldığında ortaya çıkan sonucun birbirini desteklediği görülmektedir. Kabul edilen uygulama izinleri içerisinde akıllı telefonların kamera, konum, mikrofon ve galeri özellikleri yer alırken; kabul edilmeyen özellikler içerisinde rehber, telefon ve mesaj özellikleri yer almaktadır 
Tablo 12. Uygulama İzinlerini Kabul Etme Sebebi

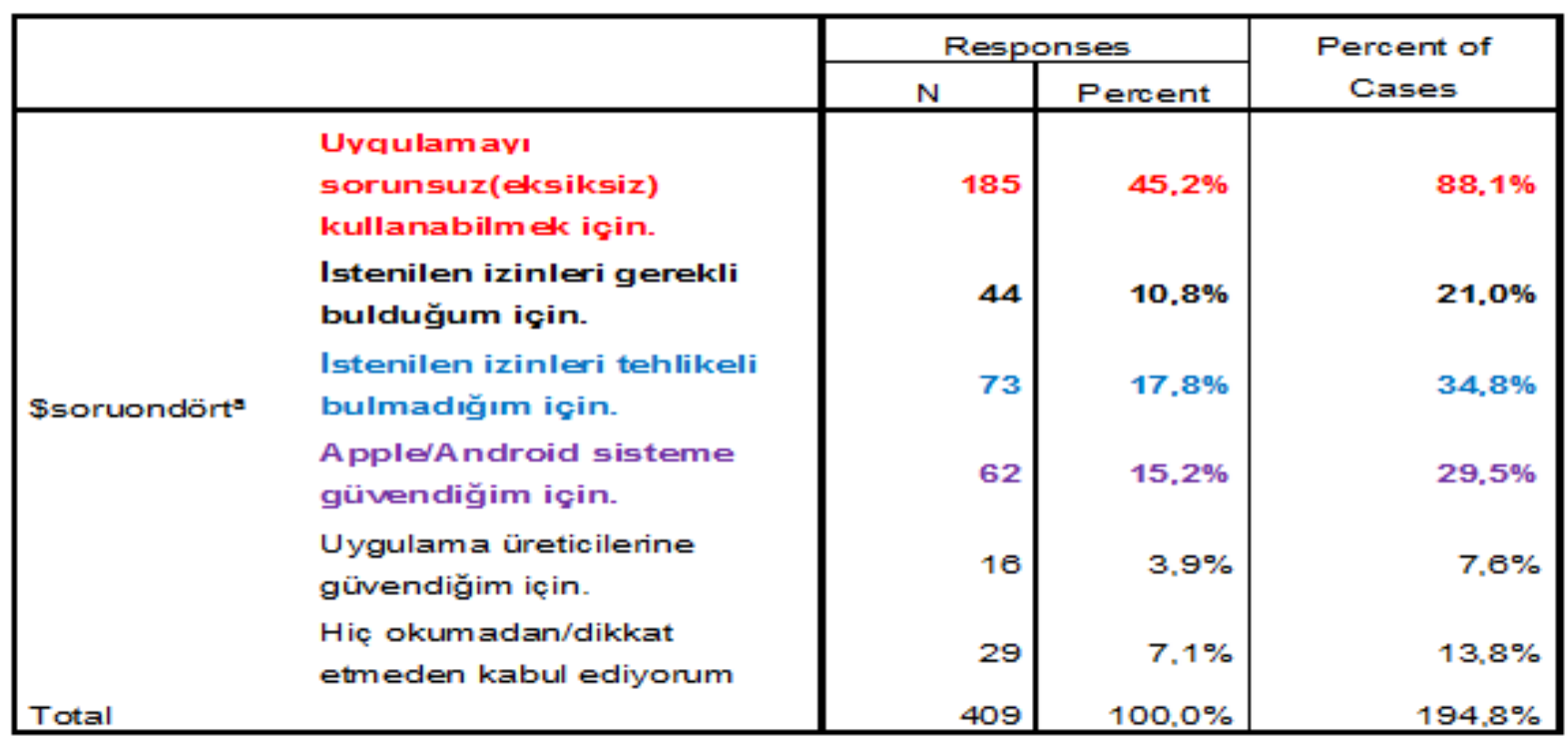

Bireylere, uygulama izinlerini kabul etme nedenleri sorulduğuna, \%88.1'i indirdikleri uygulamaları sorunsuz (eksiksiz) kullanabilmek için kabul ettiğini ifade etmişlerdir.

Tablo 13. Uygulama İzinlerini Kabul Etmeme Sebebi

\begin{tabular}{|c|c|c|c|c|}
\hline & \multicolumn{2}{|c|}{ Responses } & \multirow[t]{2}{*}{ Percent of Cases } \\
\hline & & $\mathrm{N}$ & Percent & \\
\hline \multirow{6}{*}{ \$soruonbe $s^{9}$} & $\begin{array}{l}\text { Tehlikeli olduğunu } \\
\text { düşündüğüm için. }\end{array}$ & 115 & $21.7 \%$ & $59.3 \%$ \\
\hline & $\begin{array}{l}\text { Ozel hayatın gizliliğini } \\
\text { tehdit ettiği için. }\end{array}$ & 148 & $27.9 \%$ & $76.3 \%$ \\
\hline & $\begin{array}{l}\text { Bana takip ediliyormușu m } \\
\text { hissi verdiği için. }\end{array}$ & 82 & $15.4 \%$ & $42,3 \%$ \\
\hline & $\begin{array}{l}\text { Bana huzurs uzluk hiss i } \\
\text { verdiği için. }\end{array}$ & 99 & $18.6 \%$ & $51.0 \%$ \\
\hline & $\begin{array}{l}\text { Apple/Android sisteme } \\
\text { güvenmediğim için }\end{array}$ & 25 & $4.7 \%$ & $12.9 \%$ \\
\hline & $\begin{array}{l}\text { Uygulama üreticilerine } \\
\text { güvenmediğim için. }\end{array}$ & 62 & $11.7 \%$ & $32,0 \%$ \\
\hline Total & & 531 & $100.0 \%$ & $273,7 \%$ \\
\hline
\end{tabular}

Bireylere uygulama izinlerini kabul etmeme sebepleri sorulduğunda \%76.3 oranıla “özel hayatın gizliliğini tehdit ettiği için" kabul etmediklerini söylemektedirler. Ankete katılanların \%60'1 uygulama izinlerini kabul etmeme sebeplerini genel olarak tehlikeli bulduğunu söylemiştir.

\section{Sonuç}

Akıllı telefonlar hayatımızın merkezinde yer almakta ve bize birçok konu da kolaylık sağlamaktadır. Hem iş hayatında hem de günlük hayatımızda vazgeçemediğimiz bir 
unsur haline gelen akıllı telefonlar, bilinçli kullanılmadığı zaman, bazı tehlikeleri de beraberinde getirmektedir.

Konu ile ilgili araştırmanın yapılması için üniversite öğrencilerinin seçilmesinin sebebi ise, yaş aralıkları dikkate alındığında $\mathrm{Y}$ kuşağı içerisinde yer almaları ve bu kuşağın en belirgin özelliklerinden birinin teknoloji en yoğun olarak kullanan grup olması ve bu konu da yetkinliklerinin gelişmiş olmasıdır.

Ankete katılan bireyler akıllı telefonları her zaman ve sık sık kullandı̆̆ını ve istenilen uygulama izinlerinin farkında olduğunu söylemek mümkündür. Bireyler, indirdikleri uygulamalar tarafından istenilen izinlerin farkındadır fakat, bu izinlerin içeriğini okumamaktadır.

Bireylerin çoğunluğu istenilen izinlerin özel yaşamın gizliliğini tehdit ettiğinin bilincinde fakat, özel izin gerektirdiği için yüklemekten vazgeçenlerin oranı ile vazgeçmeyenlerin oranı (Tablo 4) neredeyse birbirine eşittir. Bu durum bize tehlikenin farkında olduğu halde, önlem almayan bir kullanıcı profilini yansıtmaktadır.

En çok kullanılan mobil uygulamalar arasında, sosyal medya uygulamaları, mobil bankacılık, müzik/film uygulamaları ve e-posta uygulanmaları yer almaktadır.

İndirilen mobil uygulamaları kullanabilmek için en çok kabul edilen izinler arasında; kamera, konum bilgisi, mikrofon ve galeri bulunmaktadır. Kabul edilmeyen uygulama izinleri içerisinde ise, rehber, mesaj, telefon ve galeri bulunmaktadır.

Bireylere istenilen uygulama izinlerini neden kabul ettikleri sorulduğunda, ankete katılanların \%88,1'i indirdikleri uygulamaları sorunsuz (eksiksiz) kullanabilmek için kabul ettiklerini belirtmişlerdir. Bu durum şu örnekle açıklanabilir; "Facebook" uygulaması kullanılarak fotoğraf ve video gönderilmek istenildiğinde, Facebook uygulamasının telefonun galeri bölümüne ulaşmasına izin verilmediğinde fotoğraf yüklemesi yapamıyor, sohbet üzerinden herhangi bir görüntü veya video gönderilmemektedir. Dolayısıyla eğer uygulamalar eksiksiz olarak kullanılmak isteniyorsa, izinler kabul edilmesi gerekmektedir. Akıllı telefon uygulama izinleri üzerine daha önce yapılan çalışmalara bakıldığında literatürde öne çıkan iki çalışma dikkat çekmektedir. Bunlardan ilki, 856 ücretsiz 100 ücretli Android uygulaması üzerinde yapılan araştırmadır. Bu araştırmaya göre ücretli ve ücretsiz uygulamaların izin istekleri karşılaştırılmıştır. Ücretsiz uygulamaların internete erişim izni oranı \%86.6, ücretli uygulamaların \%65, ücretsiz uygulamaların harici depolamaya ulaşma izni \%34, ücretli uygulamaların \%50, konuma ulaşım izninde ise ücretsiz uygulamaların oranı \%33.4, ücretli uygulamaların oranı \%20'dir (Felt, Greenwood, \& Wagner, 2011). Benzer bir başka araştırmada ise kötü niyetli olduğu düşünülen uygulamalar ile Android mağazasındaki uygulamaların izinleri karşılaştırılmıştır. Android mağazasındaki uygulamaların izin istekleri sırasıyla \%68.5 internete erişim, \%24.99 telefon durumuna erişim, \%24.14 oranında ise harici belleğe erişimdir. Kötü niyetli olduğu düşünülen uygulamalarda ise \%93.38 internete erişim, \%80.99 telefon durumuna erişim ve \%64.46 oranında ise mesaj gönderme erişim izni istenmektedir (Sarma, ve diğerleri, 2012).

Araştırmalarda görüldüğü gibi indirilen uygulamaları birçoğu harici depolamaya, kameraya, telefon durumuna, internete erişim izni istemektedir. Uygulamaları indirirken 
yazılımının üreticisine dikkat etmemiz gerekmektedir. Aynı zamanda indirdiğimiz uygulamanın hangi izinleri istediğine, uygulamanın eksiksiz çalışması için istediği bu izinlerin gerekli olup olmadığını araştırmamız gerekmektedir.

\section{Kaynakça}

Ada, S. ve Tatlı, H. S., (2013). Akıllı Telefon Kullanımını Etkileyen Faktörler Üzerine Bir Araştırma. Akademik Bilişim Konferansı. Antalya: Akdeniz Üniversitesi

Çelen, F. K. (2012). Bilgi ve İletişim Teknolojilerinin Kullanımında İlköğretim Öğrencilerinin Etik Olmayan Davranışlara İlişkin Görüşlerin İncelenmesi.

Çetinkaya, B. (2010). İlköğretim ikinci kademe öğrencilerinde siber zorbalığın yaygınlığı. Yüksek Lisans Tezi. Konya: Selçuk Üniversitesi Eğitim Fakültesi Enstitüsü.

Özaydın, B. (2010). Teknoloji Kültürü ve Etik. Isparta, Türkiye: Süleyman Demirel Üniversitesi Fen Bilimleri Enstitüsü.

Adam, A. (2000). Gender and Computer Ethics. Computers and Society, 17-24.

Arıcak, O. T. (2009). Üniversite Öğrencilerindeki Siber Zorbalık Davranışlarının Bir Yordayıcısı Olarak Psikiyatrik Belirtiler. Eurasian Journal of Educational Research, 167184.

Arıcak, O. T. (2011). Siber Zorbalık: Gençlerimizi Bekleyen Yeni Tehlike. Kariyer Penceresi, $10-12$.

Arslan, Z. (2003). ABD Yüksek Mahkemesi Kararlarında Ifade Özgürlüğü, Liberal Düşünce Topluluğu. Ankara: Avrupa Komisyonu Cantekin Matbaası.

Ayas, T. (2012). Tle Relationship Between Internet and Computer Game Addiction Level and Shyness Among High School Student. Educational Sciences: Theory and Practice, 632-636.

Büyüköztürk, Ş. (2017). Sosyal Bilimciler İçin Veri Analizi El Kitabı. Ankara: Pegem Akaddemi.

Büyükfiliz, B. (2016). 18-25 Yaş Arası Genç Yetişkinlerde Problemli İnternet Kullanımı ve İletişim Becerileri Arasındaki İlişki. Yüksek Lisans Tezi. İstanbul: Üsküdar Üniversitesi Sosyal Bilimler Enstitüsü.

Baker, Ö., \& Kavşut, F. (2007). Akran Zorbalığının Yeni Yüzü: Siber Zorbalık. Eurasian Journal Of Educational Research, 31-42.

Baloğlu, Ç. (2006). İfade Özgürlüğü. Kocaeli: Kocaeli Üniversitesi Sosyal Bilimler Enstitüsü.

Beder, A., \& Ergün, E. (2015). Ortaokul Öğrencilerinin Güvenli İnternet Kullanım Durumlarının Belirlenmesi. Eğitim Bilimleri ve Uygulama, 23-41.

Cerrah, İ. (2001, Mart 24). Bilişim teknolojileri ve etik. Bilişim ve internet teknolojilerinin ceza hukuku açısından doğurduğu yeni sorunlar. (pp. 15-29). Bursa: Türkiye Cumhuriyeti İçişleri Bakanlığı.

Dülger, M. V. (2004). Avrupa İnsan Hakları Sözleşmesi'nde Düşünce Özgürlüğü. İstanbul: Galatasaray Üniversitesi Yayını.

Dedeoğlu, G. (2001). Etik ve Bilişim. Ankara: Türkiye Bilişim Derneği Yayınları. 
Dedeoğlu, G. (2006). Bilişim Toplumu ve Etik Sorunlar. Bursa: Alfa Aktüel Yayınları. Durak Batıgün, A., \& Kılıç, N. (2011). İnternet Bağımlılı̆̆ı: Kişilik Özellikleri, Psikolojik Belirtiler, Sosyal Destek ve İlişkili Bazı Sosya-demografik Değişkenler Arasındaki İlişkiler. Türk Psikoloji Dergisi, 1-10.

Erdem, Z. (2008). Öğretmen Adaylarının Bilişim Teknolojilerini Kullanımlarının Etik Açıdan Değerlendirilmesi. Dokuz Eylül Üniversitesi Eğitim Bilimleri Enstitüsü. Ersoy, A., \& Özden, M. (2011). Öğretmen Adaylarının Ödevlerinde İnternetten İntihal Yapmlarında Öğretim Elemanının Rolüne İlişkin Görüşleri. İlköğretim Online, 608619.

Esen, E., \& Siyez, D. M. (2011). Ergenlerde İnternet Bağımlılı̆̆ını Yordayan Psiko-sosyal Değişkenlerin İncelenmesi. Türk Psikolojik Danışma ve Rehberlik Dergisi, 127-138.

Felt, A. P., Greenwood, K., \& Wagner, D. (2011). The Effectiveness of Application Permissions. 2nd USENIX Conference on Web Application Development (WebApps '11) (pp. 75-86). Portland: USENIX Association.

Fidan, M. (2016). Bilişim Etiği Boyutlarına Göre Bilişim Teknolojileri Ve Yazılım Dersi Öğretim Programı Kazanımlarının İncelenmesi. Kastamonu Ĕ̆itim Dergisi, 1641-1654. Gökmen, Ö. F., \& Akgün, Ö. E. (2014). Bilgisayar ve Öğretim Teknolojileri Eğitimi Öğretmen Adaylarının Bilişim Güvenliği Bilgilerinin Çeşitli Değişkenlere Göre İncelenmesi. Çukurova Üniversitesi Eğitim Fakültesi Dergisi, 61-84.

Gattiker, U. E., \& Kelley, H. (1999). Morality And Computer: Attitudes And Differences In Moral Judgments. Information Systems Research, 233-254.

Genç, Z., Kazez, H., \& Fidan, A. (2013). Çevrimiçi Etik Dışı Davranışlarının Belirlenmesi İçin Bir Ölçek Uyarlama Çalışması,. Akademik Bilişim 2013 (pp. 194-197). Antalya: Akdeniz Üniversitesi.

Godwin, R. (2011). Emerging Technologies: Mobile Apps for Language Learning. Language Learning E Technology, 15(2), 2-11.

Haines, R., \& Leonard, L. K. (2007). Individual Characteristics and Ethical Decisionmaking in an IT context. Journal of Management $\mathcal{E}$ Data Systems,, 5-20.

Ünver, H. (2016). Siber Zorbalık ile Problemli İnternet Kullanımı ve Riskli Internet Davranışı Arasındaki İlişki ve Bu Değişkenlerin Çeşitli Demografik Özellikler Açısından İncelenmesi. Yüksek Lisans Tezi. Ankara: Gazi Üniversitesi Eğitim Bilimleri Enstitüsü.

Karagöz, K. (2004). İfade Özgürlüğü ve İnsan Hakları Avrupa Mahkemesi Kararlarında Sınırlandırılması Sorunu. Ankara, Türkiye: Ankara Üniversitesi Sosyal Bilimler Enstitüsü.

Karahisar, T. (2014). İnternette Çocukları Bekleyen Riskler ve Medya Okuryazarlığı. The Turkish Online Journal of Design, Art and Communication, 82-95.

Karasar, N. (2004). Bilimsel Araştırma Yönetmi. Ankara: Nobel Yayınları.

Kavza, U. (2010). Veri Madenciliğinde Mahremiyetin Sağlanması. Yüksek Lisans Tezi. Kocaeli: Gebze Yüksek teknoloji Enstitüsü Mühendislik ve Fen Bilimleri Enstitüsü. 
Kazaskeroğlu, E., Özpınar , A., \& Öz, Ö. (2010). Bilgiye Erişim, Paylaşım Ve Bilgi Teknolojileri Alanında Etik Olmayan Davranışlar Ve Sebepleri. Ankara, Türkiye: III. Ağ ve Bilgi Güvenliği Sempozyumu.

Kiera, J., \& Cronan, T. (1998). How Men And Woman View Ethics. Communications Of The ACM, 70-76.

Kim, S., \& Hovav, A. Z. (2011). The impact of smart phone usability on group task performance in a university environment: media synchronicity perspective. International Conference on Information Resources Management (CONF-IRM). Seul.

Kuzu, E. B., \& Becit, G. (2008). Bilgisayar Etiği Bilgisayar ve Öğretim Teknolojileri Eğitimi Programlarında Kendine Ne Kadar Yer Buluyor?,. 8th International Education Technology Conference, (pp. 284-288). Eskişehir.

Lau, W., \& Yuen, A. (2014). Internet Ethics Of Adolescents: Understanding Demographic Differences. Computer $\mathcal{E}$ Education, 378-385.

Mason, R. O. (1986). Four Ethical Issues of Information Age. Mis Quarterly, 5-11.

Metin, M. (2015). Kuramdan Uygulamaya Eğitimde Bilimsel Araştırma Yöntemleri. Ankara: Pegem Yayınları.

Peker , A., \& Eroğlu, Y. (2010). Erkek Öğrencilerde Siber Zorba ve Kurban Olmanın Yordayıcısı Olarak İnternet Bağımlılı̆̆ı. 4. Uluslararası Bilgisayar ve Öğretim Teknolojileri Sempozyumu (pp. 862-867). Konya: Maya Akademi.

Perry, B. (2010). Exploring Academic Misconduct: Some Insights Into Student Behaviour. Active Learning In Higher Education, 97-108.

Sarma, B., Li, N., Gates, C., Potharaju, R., Nita-Rotaru, C., \& Molloy, I. (2012). Android Permissions: A Perspective Combining Risks and Benefits. Symposium on Access Control Models and Technologies (SACMAT) (pp. 13-22). Newark, USA: Rutgers University.

Solmaz, B., Tekin, G., Herzem, Z., \& Demir, M. (2013). İnternet ve Sosyal Medya Kullanımı Üzerine Bir Uygulama. Selçuk İletişim, 23-32.

Şahin, C. (2011). An Analysis of Internet Addiction Levels of Individuals According to Various Variables. The Turkish Online Journal of Education Technology, 60-66.

Türk Ceza Kanunu. (2004). Retrieved from http://www.tbmm.gov.tr/kanunlar/k5237.html Türk Patent Enstitüsü. (2013). Fikri Mülkiyet ve Küçük Orta Ölçekli İşletmler. Retrieved from http://www.turkpatent.gov.tr/dosyalar/yayinlar/bilgikitapciklari/fikrimlkytkobi.pdf Takemura, T., Tanaka, H., \& Matsuura , K. (2011). Analysis of Awareness Gap between Security Managers and Workers in an Organization with Regard to the Effectiveness of the Informations Security Measures. Journal of Information Prowessing, 253-262.

Torun, Ö. (2007). Resmi Ortaokul Kurumlarında Öğrenim Gören Öğrencilerin İnternet Etiğine İlişkin Algılarının İncelenmesi. MArmara Üniversitesi Eğitim Bilimler Enstitüsü. 
Tosun, N., Geçer, A., \& Kaşıkçı, D. N. (2016). Öğretmen Adaylarının Internet Etiği Algıları ve Kontrol Odağı Algıları Arasındaki İlişkinin İncelenmesi. Açıköğretim Uygulamaları ve Araştırmaları Dergisi, 2(4), 82-103.

Uysal, Ö. (2006). Öğretmen Adaylarının Bilgisayar Etiğine İlişkin Görüşleri. Eskişehir: Anadolu Üniversitesi Eğitim Bilimleri Enstitüsü.

Vigra-Taglianti, F., Brambilla, R., Priotto, B., Angelino, R., Cuomo, G., \& Diecidue, R. (2017). Problemmatic Internet Use Among High School Student: Prevalence,Associated Factors and Gender Differences. Psychiatry Research, 163-171.

Zeybek, G. (2011). Bilgisayar Meslek Dersi Alan Ortaöğretim Öğrencilerinin Bilişim Teknolojilerini Kullanımlarının Etik Açıdan İncelenmesi. Konya. 